\title{
EFFECTS OF A PROBIOTIC MILK DRINK ON SALIVARY TUMOR NECROSIS FACTOR-ALPHA IN CHILDREN WITH ACUTE LYMPHOBLASTIC LEUKEMIA IN THE INDUCTION PHASE
}

\author{
JENNIFER SURJA PARIAPUTRA, SARWORINI B BUDIARDJO*, MARGARETHA SUHARSINI \\ Department of Pediatric Dentistry, Faculty of Dentistry, Universitas Indonesia, Jakarta 10430, Indonesia. \\ Email: sarworinibagio@yahoo.com
}

Received: 23 October 2017, Revised and Accepted: 21 November 2017

\section{ABSTRACT}

Objective: The aim of this study was to investigate the effects of the short-term use of a probiotic milk drink on salivary tumor necrosis factor-alpha (TNF- $\alpha$ ) in children with acute lymphoblastic leukemia (ALL) during the induction phase of chemotherapy.

Methods: A randomized, case-controlled clinical trial was carried out. The samples of the study were collected from 11 children with ALL and 11 healthy children as the control. Both groups received a probiotic milk drink. The probiotic milk drink contained Lactobacillus casei $\left(6.5 \times 10^{9}\right.$ colony forming unit/mL). The subjects were instructed to rinse $5 \mathrm{~mL}$ of probiotic milk drink for $30 \mathrm{~s}$ over the course of 2 weeks. Unstimulated saliva samples were collected from patients at baseline and 1 and 2 weeks after rinsing with the probiotic milk drink. The levels of TNF- $\alpha$ were determined using a human TNF- $\alpha$ enzyme-linked immunosorbent assay kit.

Results: The salivary TNF- $\alpha$ levels in the experimental group decreased but not to a statistically significant degree (p $>0.05$ ) when comparing the baseline with weeks 1 and 2 after rinsing. There was a significant decrease of salivary TNF- $\alpha$ levels in the control group (p<0.05) when comparing the baseline with 1 and 2 weeks after rinsing. The concentration of salivary TNF- $\alpha$ in the experimental group was higher than in the control group $(\mathrm{p}<0.05)$.

Conclusion: This study demonstrates the effect of a short-term intake of a probiotic milk drink on children with ALL during the induction phase of chemotherapy. The results show a reduction of salivary TNF- $\alpha$ after taking the probiotic milk drink after 1 week and 2 weeks, although the results were not statistically significant.

Keywords: Acute lymphoblastic leukemia, Gingivitis, Salivary tumor necrosis factor-alpha, Probiotics.

(C) 2018 The Authors. Published by Innovare Academic Sciences Pvt Ltd. This is an open access article under the CC BY license (http://creativecommons. org/licenses/by/4. 0/) DOI: http://dx.doi.org/10.22159/ajpcr.2018.v11i2.23242

\section{INTRODUCTION}

Leukemia is a malignant disease that originates from blood-forming tissues, such as bone marrow, causing many blood cells to be produced and enter the bloodstream [1]. This malignancy is followed by anomalously shaped leukocytes. Acute lymphoblastic leukemia (ALL) is the most common type of leukemia [2]. ALL accounts for $75 \%$ of all acute leukemia [3]. In children, it occurs in ages 2-5, and it occurs more frequently in boys than girls [4]. The cause of ALL remains largely unknown, although many conditions may contribute to its development [5]. The treatment modalities for ALL include chemotherapy [6].

Chemotherapy is the main treatment for ALL patients [7]. Chemotherapy consists of three phases: Induction, consolidation, and maintenance. Chemotherapy may cause many problems in the oral cavity, such as gingival bleeding, mucositis, and candidiasis [8]. Previous studies show that ALL children who have had chemotherapy treatment have a high level of salivary tumor necrosis factor-alpha (TNF- $\alpha$ ) [9]. TNF- $\alpha$ is one of the most important inflammatory mediators that plays a big role in the inflammatory process [10]. Overproduction of TNF- $\alpha$ caused by chemotherapeutic agents and systemic conditions may lead to pathological conditions, such as gingival inflammation [10].

According to the World Health Organization, probiotic bacteria are defined as living microorganisms, which, when administered in adequate amounts, confer a health benefit to the host [11]. Their mechanisms of action are not fully known, but the general theory is that good microorganisms compete with pathogens and exert therapeutic effects locally and systemically by influencing the immune system [11]. Probiotic bacteria are divided into two major strains: Lactobacillus and Bifidobacterium [11].
Probiotic bacteria are used for dairy products, such as milk, yoghurt, cheese, chewing gum, and ice cream [11]. Probiotics have many proposed modes of action, such as preventing the adhesion of pathogens to host tissues and stimulating and/or modulation the mucosal immune system. Probiotics have the ability to inhibit the production of proinflammatory cytokines in saliva and improve gingival health [12].

Lactobacillus casei is one of the most common strains that is added into drink products, such as fermented milk drinks or yoghurt [13]. Moreover, a study by Imran et al. reported that there were no adverse effects from probiotic milk drinks containing L. casei. This showed the safety of probiotic milk drinks [13].

L. casei has the ability to attach to a mucosal surface as a barrier to pathogenic bacteria and suppress the growth of Actinobacillus actinomycetemcomitans, Porphyromonas gingivalis, Prevotella intermedia, and Streptococcus mutans [14]. Previous studies in vivo have suggested that probiotic strains of Lactobacillus could reduce moderate to severe gingival inflammation by modulating the immune system and attaching to gingival tissue [15]. There is no study that shows effects of probiotic on salivary TNF- $\alpha$ in ALL children. This study is considered as a preliminary study. The aim of the present study was to investigate the effect of short-term use of probiotic milk drinks on the level of TNF- $\alpha$ in saliva in ALL children during the induction phase of chemotherapy.

\section{METHODS}

\section{Design of study}

A randomized, case-controlled clinical trial was carried out to determine the TNF- $\alpha$ level in saliva. Samples were collected $2 \mathrm{~h}$ before, 7 days after, 
and 14 days after both the experimental and control groups rinsed their mouths with a probiotic milk drink.

\section{Subjects}

The experimental group consisted of 11 ALL children of ages ranging from 6 to 17 years old who entered the Dharmais Cancer Hospital in Jakarta. Patients with high-risk ALL, entered induction phase of chemotherapy, the presence of at least two buccal marginal sites with moderate acute gingival inflammation, and who had no habitual use of probiotic products met the inclusion criteria. Children with rampant decay and children with open caries lesions were excluded. The control group was made up of 11 systemically healthy children ranging from 6 to 17 years in St. Cecilia School in Jakarta, none of whom met the experimental group's exclusion criteria. Once the purpose of the study was explained to the parents and guardians, they all signed a document indicating their informed consent. Both groups were given a probiotic milk drink. After baseline examination and sampling, follow-up registrations and samplings were conducted one and 2 weeks after baseline. The probiotic milk drink contained L. casei at a dose of $6.5 \times 10^{9}$ colony forming units $/ \mathrm{mL}$. The participants were instructed to actively rinse $5 \mathrm{~mL}$ of the probiotic milk drink for $30 \mathrm{~s}$ daily in the morning at least $1 \mathrm{~h}$ after taking food. The study was approved by the Ethics Committee in Dharmais Cancer Hospital, Jakarta.

\section{Clinical examination}

The clinical examination was carried out using a halogen light headlamp and a flat mouth mirror with the patient lying down. The first evaluation was made $2 \mathrm{~h}$ before rinsing with the probiotic milk drink, the second one was made at 7 days after rinsing, and the third one was made at 14 days after rinsing.

\section{Collecting saliva samples}

After recording the clinical findings, $2 \mathrm{~mL}$ of non-stimulated saliva was collected in a sterile tube and taken to the Oral Biology Laboratory Universitas Indonesia on ice. The sample was centrifuged for 20 min. The supernatant was transferred to another sterile tube and stored at $-80^{\circ} \mathrm{C}$ until processed.

\section{Determining salivary TNF- $\alpha$ level}

The salivary TNF- $\alpha$ levels were determined by a human TNF- $\alpha$ enzymelinked immunosorbent assay kit (Elabscience; Texas, USA). The results were expressed in $\mathrm{pg} / \mathrm{mL}$.

\section{Statistical analysis}

A comparison of the results was done using SPSS version 20. To compare the groups, the Mann-Whitney U-test was applied. An analysis of variance was used to determine the effect of the probiotic milk drink, and the Bonferroni test was used as the post-test with a significance value of $\mathrm{p}<0.05$.

\section{RESULTS}

Salivary TNF- $\alpha$ concentrations in the experimental group showed a decrease of this cytokine, and they were evaluated during baseline $(31.279 \pm 14.791 \mathrm{pg} / \mathrm{mL})$, and 1 week $(30.130 \pm 16.255 \mathrm{pg} / \mathrm{mL})$, and 2 weeks $(28.236 \pm 15.919 \mathrm{pg} / \mathrm{mL})$ after rinsing with the probiotic milk drink. No statistically significant differences were found, however Table 1.

On the other hand, a statistically significant difference was found $(p<0.05)$ in the control group between the TNF- $\alpha$ concentration at baseline $(21.454 \pm 411 \mathrm{pg} / \mathrm{mL})$ and at 1 week $(13.130 \pm 3.212 \mathrm{pg} / \mathrm{mL})$ and 2 weeks $(8.558 \pm 3.406 \mathrm{pg} / \mathrm{mL}$ ) (Table 2).

The difference in the salivary TNF- $\alpha$ concentration between the two groups was statistically significant $(\mathrm{p}<0.05)$ with a level of $29.911 \pm 15.221 \mathrm{pg} / \mathrm{mL}$ for the experimental group and $14.381 \pm 6.314 \mathrm{pg} / \mathrm{mL}$ for the control group (Table 3 ).
Table 1: Concentration of salivary TNF- $\alpha(\mathrm{pg} / \mathrm{mL}$, mean \pm SD) of the experimental group in saliva at baseline and at designated time intervals during and after use of a probiotic milk drink containing L. casei

\begin{tabular}{lll}
\hline Time & Experimental group $(\mathbf{p g} / \mathbf{m L})(\mathbf{m e a n} \pm$ SD) & $\mathbf{p}$ \\
\hline Baseline & $31.279 \pm 14.791$ & \\
1 week & $30.130 \pm 16.255$ & $\mathrm{p}>0.05$ \\
2 weeks & $28.236 \pm 15.919$ & $\mathrm{p}>0.05$ \\
\hline
\end{tabular}

No statistically significant difference compared to baseline $(p>0.05$, repeated measures ANOVA). TNF- $\alpha$ : Tumor necrosis factor-alpha, SD: Standard deviation L. casei: Lactobacillus casei

Table 2: Concentration of salivary TNF- $\alpha(\mathrm{pg} / \mathrm{mL}$, mean \pm SD) of the control group in saliva at baseline and at designated time intervals during and after use of a probiotic milk drink containing L. casei

\begin{tabular}{lll}
\hline Variable/time & Control group $(\mathbf{p g} / \mathbf{m L})(\mathbf{m e a n} \pm$ SD) & $\mathbf{p}$ \\
\hline Baseline & $21.454 \pm 3.411$ & \\
1 week & $13.130 \pm 3.212^{*}$ & $\mathrm{p}<0.05^{*}$ \\
2 weeks & $8.558 \pm 3.406^{*}$ & $\mathrm{p}<0.05^{*}$ \\
\hline
\end{tabular}

*Statistically significant difference compared to baseline $(\mathrm{p}<0.05$, repeated measures ANOVA). TNF- $\alpha$ : Tumor necrosis factor-alpha, SD: Standard deviation, L. casei: Lactobacillus casei

Table 3: Concentration of salivary TNF- $\alpha$ between the two groups

\begin{tabular}{lll}
\hline Variable/time & $\begin{array}{l}\text { Concentrations of } \\
\text { TNF- } \alpha(\mathbf{p g} / \mathbf{m L})(\text { mean } \pm \text { SD) }\end{array}$ & $\mathbf{p}$ \\
\hline $\begin{array}{l}\text { Experimental } \\
\text { group (ALL children) }\end{array}$ & $29.911 \pm 15.221$ & $\mathrm{p}<0.05^{*}$ \\
$\begin{array}{l}\text { Control group (healthy } \\
\text { children) }\end{array}$ & $14.381 \pm 6.314$ & \\
\hline
\end{tabular}

*Statistically significant difference compared to baseline $(\mathrm{p}<0.05$,

Mann-Whitney U-test). TNF- $\alpha$ : Tumor necrosis factor-alpha, SD: Standard deviation, ALL: Acute lymphoblastic leukemia

\section{DISCUSSION}

This study was undertaken to investigate the inflammatory response in the oral cavity after short-term exposure to probiotic bacteria in ALL children during the induction phase of treatment, and this, to our knowledge, is the first clinical trial on the issue. The main finding was that there was a decrease of the pro-inflammatory cytokine TNF- $\alpha$ following rinsing with a probiotic milk drink containing L. casei for $30 \mathrm{~s}$ each day for 2 weeks, even though the results did not show a statistically significant decrease.

Children who suffer from ALL who are treated with chemotherapy show acute complications in the oral cavity. In ALL, the characteristic symptoms are gingival inflammation, mucositis, xerostomia, and dental caries [6]. Gingival inflammation is usually generalized and varies in severity. The gingival tissue in ALL children is usually deep red, swollen, and prone to bleeding [1]. The gingival swelling is due to leukemic infiltration in gingival tissue, and the gingival tissue destruction is caused by chemotherapeutic agents [3].

From the results (Table 3), we can see that salivary TNF- $\alpha$ in the experimental group was higher than in the control group. One possible reason for this is the use of methotrexate, which is one of the most destructive chemotherapeutic agents [9]. Previous studies showed that high doses of methotrexate during the induction phase may lead to an increase of TNF- $\alpha$ levels in the oral cavity, which causes a severe pathological condition of the gingival tissue [9]. TNF- $\alpha$ produced and secreted by antigen-presenting cells, such as monocytes, macrophages, 
fibroblasts, and dendritic cells, is the central mediator for tissue damage [16]. Chemotherapeutic agents can cause the release of TNF- $\alpha$ from the epithelial tissues [10]. TNF- $\alpha$ is the most important cytokine that plays a role in periodontal diseases. Release of TNF- $\alpha$ not only causes tissue destruction but also speeds up and induces gingival inflammation events [17]

The role of probiotics in the oral cavity is not fully understood, but it is commonly explained by a combination of local and systemic immunomodulation as well as non-immunomodulation mechanisms [18]. A study conducted by Twetman et al. reported that there was a reduction of TNF- $\alpha$ levels in the gingival crevicular fluid after 2 weeks of administering probiotics in the form of a chewing gum [19]. Another study conducted by Nadkerny et al. reported that there was a significant reduction in the plaque index, gingival index, and oral hygiene index after 4 weeks of rinsing with a probiotic mouthwash [20]. A study conducted by Staab et al. reported that a probiotic milk drink containing L. casei may reduce the amount of matrix metalloproteinase-3 after drinking the probiotic milk drink for 8 weeks [21].

Probiotics are administered in many forms in dairy products, such as cheese, and in food supplements, such as tablets and chewing gums [12]. These routes of administration may not provide the prolonged attachment of the probiotic with the oral mucosa. Thus, in our study, we used a probiotic that was delivered in a fermented milk drink [13].

The probiotic milk drink was administered once daily. They were taken in the morning an hour after breakfast intake. We gave time after food intake to allow for the removal of food remnants by the washing effect of saliva. The subjects were instructed to rinse for $30 \mathrm{~s}$ before spitting the probiotic milk drink out. After rinsing, the subjects were not allowed to eat or drink for $30 \mathrm{~min}$. This was done to facilitate the contact between the probiotic milk drink and as much of the oral mucosal surface as possible, especially the gingival tissues.

In this study, we used a probiotic milk drink that contained 6.5 billion L. casei in a $65-\mathrm{mL}$ bottle. The concentration of this probiotic milk drink was higher than the dose needed to be effective in the gastrointestinal tract [13].

No statistically significant changes were found in salivary TNF- $\alpha$ concentration after intervals of 1 week and 2 weeks when compared to baseline (Table 1). The reason why may be attributed to the subjects' systemic conditions and the chemotherapeutic agent, which was delivered every 2 days to the ALL children during the induction phase. High doses of methotrexate, which is used as a chemotherapeutic agent to kill leukemic cells, can damage the gingival tissues severely [9]. A previous study conducted by Morales-Rojas et al. showed that administration of methotrexate after $96 \mathrm{~h}$ increased cytokine levels, including TNF- $\alpha$ [9].

In the control group (Table 2), we found there was a statistically significant decrease of salivary TNF- $\alpha$ concentration. This may have been caused by the control group's systemically healthy condition, which may have caused lower salivary TNF- $\alpha$ levels and a better response to probiotic treatment. A study conducted by Staab et al. reported that the host's immune response was modulated by L. casei in experimental gingivitis subjects when no mechanical cleaning procedures were done [21]

We recommend that future studies be continued under this same approach that considers an increase in sample size, an increase in the period of rinsing with the probiotic milk drink, and a longer interval of evaluation.

\section{CONCLUSION}

This research reported the effect of the short-term intake of a probiotic milk drink on ALL children during the induction phase of their treatment. The results showed a reduction of salivary TNF- $\alpha$ when rinsing with a probiotic milk drink after 1 week and 2 weeks, even though the result was not statistically significant. This might be caused by the effects of chemotherapy and the systemic condition of ALL children. The results of this study suggest that researchers should conduct further studies to investigate the long-term effects of using a probiotic to manage gingival inflammation on ALL children in the induction phase of chemotherapy.

\section{ACKNOWLEDGMENT}

The Publication of the manuscript is supported by Universitas Indonesia in 2017. This study was designed, conducted, and coordinated by Professor Sarworini B. Budiardjo and Professor Margaretha Suharsini as the principal investigator, provided conceptual and ethical guidance for all aspect of the project. Jennifer Surja Pariaputra performed, analyzed the data, and write the manuscript.

\section{CONFLICT OF INTEREST}

There is no conflict of interest

\section{REFERENCES}

1. Ponce-Torres A, Ruiz-Rodriguez E, Alejo-Gonzalez M, HernandezSierra F, Pozoz-Gullen J. Oral manifestations in pediatric patients receiving chemotherapy for acute lymphoblastic leukemia. J Clin Pediatr Dent 2010;34:275-80.

2. Valéra MC, Noirrit-Esclassan E, Pasquet M, Vaysse F. Oral complications and dental care in children with acute lymphoblastic leukaemia. J Oral Pathol Med 2015;44:483-9.

3. Nasim VS, Shetty YR, Hegde AM. Dental health status in children with acute lymphoblastic leukemia. J Clin Dent 2007;31:210-3

4. Hedge AM, Joshi S, Rai K. Evaluation of oral hygiene status, salivary characteristics and dental caries experience in acute lymphoblastic leukemic. J Clin Pediatr Dent 2011;35:319-24.

5. Azher U, Shiggaon N. Oral health status of children with acute lymphoblastic leukemia undergoing chemotherapy. Indian J Dent Res 2013;24:523.

6. Rímulo AL, Ferreira MC, Abreu MH, Paiva SM. Chemotherapyinduced oral mucositis in a patient with acute lymphoblastic leukaemia. J Peadiatr Dent 2011;12:124-8.

7. Gupta M, Dahiya J, Marwaha RK, Dureja H. Therapies in cancer treatment: An overview. Int J Pharm Pharm Sci 2015;7:1-9.

8. Antony A, Joel JJ, Shetty J, Umar NF. Identification and analysis of adverse of drug reactions asscociated with cancer chemotherapy in hospitalized patients. Int J Pharm Pharm Sci 2016;8:448-51.

9. Morales-Rojas T, Julia C, Viera N, Moro A, Alejandra A. Proinflammatory cytokines during the initial phase of oral mucositis in patients with acute lymphoblastic leukaemia. J Peadiatr Dent 2012;22:191-7.

10. Gholizadeh N, Mehdipoor M, Sajadi H, Moosavi M. Palifermin and chlorhexidine mouthwashes in prevention of chemotherapy-induced mucositis in children with acute lymphocytic leukemia: A randomized controlled trial. J Dent Shiraz Univ Med Sci 2016;17:343-7.

11. Punia V, Punia SK, Khandelwal M, Sharma V. The mechanism of action of probiotics: Current opinion in oral health. J Dent Sci 2012;4:90-5.

12. Dhawan R, Dhawan S. Role of probiotics on oral health: A randomized, double-blind, placebo-controlled study. J Int Dent 2013;3:71-8.

13. Imran F, Das S, Padmanabhan S, Rao R, Suresh A, Bharath D. Evaluation of the efficacy of a probiotic drink containing L. casei on the levels of periodontopathic bacteria in periodontitis: A clinico-microbiologic study. Indian J Dent Res 2015;26:462-8.

14. Yanine N, Araya I, Brignardello-Petersen R. Effects of probiotics in periodontal diseases: A systematic review. J Clin Oral Invest 2013; 17:1627-34

15. Lee J, Kim S, Ko S, Ouwehand AC, Ma DS. Modulation of the host response by probiotic Lactobacillus brevis CD2 in experimental gingivitis. Oral Dis 2015;21:705-12.

16. Varghese SS, Thomas H, Jayakumar ND, Sankari M, Lakshmanan R. Estimation of salivary tumor necrosis factor-alpha in chronic and aggressive periodontitis patients. Contemp Clin Dent 2015;6:152-7.

17. Yousefimanesh H, Maryam R, Mahmoud J, Mehri GB, Mohsen T. Evaluation of salivary tumor necrosis factor-alpha in patients with the chronic periodontitis: A case-control study. Indian J Soc Periodontol 
$2013 ; 17: 737-40$

18. Hallström H, Lindgren S, Yucel-Lindberg T, Dahlén G, Renvert S, Twetman S. Effect of probiotic lozenges on inflammatory reactions and oral biofilm during experimental gingivitis. J Clin Periodontol 2013;71:828-33.

19. Twetman S, Derawi B, Keller M, Ekstrand KI, Yucel-Lindberg LA, Steckse C. Short-term effect of chewing gums containing probiotic Lactobacillus reuteri on the levels of inflammatory mediators in gingival crevicular fluid. J Clin Dent 2009;67:19-24

20. Nadkerny PV, Ravishankar PL, Pramod V. A comparative evaluation of the efficacy of probiotic and chlorhexidine mouthrinses on clinical inflammatory parameters of gingivitis: A randomized controlled clinical study. J Indian Soc Periodontol 2015;19:633-40.

21. Staab B, Erick S, Knofler G. The influence of a probiotic milk drink on the development of gingivitis: A pilot study. J Clin Periodontol 2009;36:850-6. 